
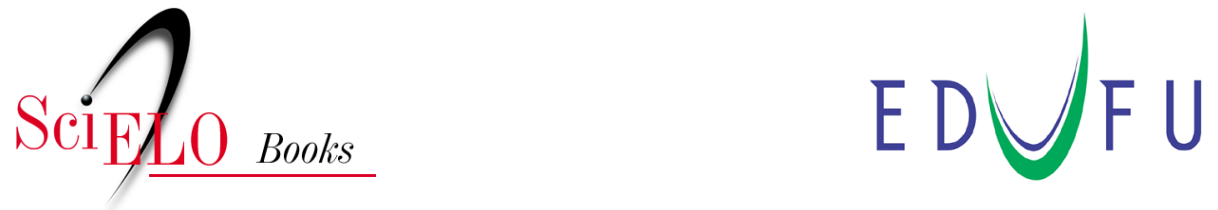

\title{
Letramento acadêmico no curso de Letras - Português
}

\author{
Maria de Lourdes Guimarães de Carvalho
}

\section{SciELO Books / SciELO Livros / SciELO Libros}

CARVALHO, M.L.G. Letramento acadêmico no curso de Letras Português. In: AGUSTINI, C., and ERNESTO, B., eds. Incursões na escrita acadêmico-universitária: letramento, discurso, enunciação [online]. Uberlândia: EDUFU, 2017, pp. 193-219. ISBN: 978-6586084-26-9. https://doi.org/10.7476/9786586084269.0012.

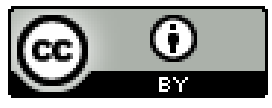

All the contents of this work, except where otherwise noted, is licensed under a Creative Commons Attribution 4.0 International license.

Todo o conteúdo deste trabalho, exceto quando houver ressalva, é publicado sob a licença Creative Commons Atribição 4.0. 


\section{Letramento acadêmico no curso de Letras - Português}

Maria de Lourdes Guimarães de Carvalho

Coincidentemente com o processo de democratização do ensino superior, investigações referentes à escrita acadêmica têm sido feitas. Por exemplo, pesquisadores franceses como Boch e Grossmann (2002) atribuem as causas das dificuldades de escrita dos universitários às características específicas de escrita acadêmica. Delcambre e Jovenet (2002), objetivando analisar a prática da escrita na universidade, relacionam essas dificuldades a fatores como: os novos tipos de discurso com os quais os acadêmicos se deparam na universidade, as novas práticas de pesquisa escrita e a distância entre a cultura escrita e as práticas de escrita na universidade.

No Brasil, especificamente com relação às práticas de leitura e escrita de textos do gênero acadêmico por alunos dos cursos de licenciatura, pesquisadores como Assis, Mata e Perini-Santos (2003); Matencio (2006); Motta-Roth e Hendges (2010), não só apontam crescentes dificuldades, mas também afirmam que o gerenciamento das vozes do discurso mostra-se como um ponto crítico das produções dos graduandos.

Tendo em vista essas considerações, o problema de pesquisa que propusemos responder foi: quais são as marcas linguístico-textuais e discursivas que indiciam o letramento acadêmico de alunos do curso de Licenciatura em Letras da Universidade Estadual de Montes Claros Unimontes? Nesse sentido, o objetivo geral foi evidenciar o letramento acadêmico desses alunos. 
Apesar da grande variedade de gêneros do domínio acadêmico, este trabalho está centrado no gênero resenha, particularmente a escrita por professores em formação. Considera-se que é um gênero recorrente no âmbito universitário e deve ser compreendido como auxiliar no desenvolvimento das capacidades de síntese, interpretação e crítica, levando o estudante a pesquisar, ler e elaborar textos científicos mais complexos. É um gênero importante, ainda, para o desenvolvimento da mentalidade científica, e, nesse sentido, suas normas, convenções e modos de escrita deverão ser estudados para que o acadêmico possa, ao produzi-lo, evidenciar seu letramento.

A importância da investigação reside no fato de que, durante a trajetória de formação, os acadêmicos são solicitados a lidarem com diferentes gêneros, seja lendo, seja retextualizando e emitindo suas posições acerca das temáticas estudadas nas diferentes disciplinas do currículo. Sabe-se que características semelhantes à resenha são encontradas em relatos de experiência, artigos, monografias, dissertações, teses, prefácios, apresentações de livros, dentre outros, mais especificamente na seção geralmente intitulada fundamentação teórica ou pressupostos teóricos.

Além disso, como profissionais da área, deverão recorrer a tais ações de forma a contribuir para o letramento de seus alunos. Sobre isso, Mata, ao defender que a leitura e a produção de textos escritos são fundamentais na formação de qualquer graduando, assim afirma: "Em cursos de formação de professores, como é o caso investigado, essa importância é ainda maior já que cabe ao professor a tarefa de inserir outros sujeitos em práticas letradas" (Mata, 2008, p.11).

Há que ser considerado, ainda, que conhecer operações linguísticas e textuais requeridas para a produção da resenha é essencial para o efetivo exercício de construção de autoria do acadêmico, uma vez que a resenha é um gênero que requer, também, posicionamento críticovalorativo, diante dos discursos. Considera-se que o estudante deve não só compreender o que lê, mas também estar ciente de que, conforme afirma Kleiman "[...] a concepção social da escrita implica desenvolver sujeitos plenamente letrados, que têm familiaridade com diversas práticas discursivas letradas de diversas instituições" (Kleiman, 2002, p.34). Nesse sentido, considera-se que, ao praticar a escrita acadêmica, ocorre o uso epistêmico da escrita, que é escrever não apenas para divulgar, mas também para transformar a experiência da escrita em oportunidade para adquirir e para demonstrar conhecimentos. 
Partimos da hipótese de que os ingressantes em um curso de licenciatura não se engajam de imediato nas práticas letradas do domínio acadêmico, já que, nesse novo contexto, são solicitados a ler e a produzir novos gêneros como parte do currículo ou para inserção nos trabalhos de investigação, com os quais ainda não tiveram contato de forma sistemática.

Bakhtin, baseando-se na concepção dialógica da linguagem, defende que o domínio de um gênero é um comportamento social:

São muitas as pessoas que, dominando magnificamente a língua, sentem-se logo desamparadas em certas esferas da comunicação verbal, precisamente pelo fato de não dominarem na prática, as formas de gênero de uma dada esfera. Não é raro o homem que domina perfeitamente a fala numa esfera da comunicação cultural, saber fazer explanação, travar uma discussão científica, intervir a respeito de problemas sociais, calarse ou então intervir de maneira muito desajeitada numa conversa social. Não é por causa de uma pobreza de vocabulário ou de estilo, mas de uma inexperiência, de dominar o repertório de gêneros da conversa social [...] (Bakhtin, 1997, p.303).

Sendo assim, ao ingressarem na universidade, os acadêmicos podem não ser letrados no que se refere ao letramento acadêmico, entendido como a prática de leitura e de produção de um gênero que envolve a utilização de um vocabulário especializado, de novas terminologias e de novos conceitos. Nesse processo, a leitura e a escrita ocorrem com o propósito de aprender por meio da manipulação do exame, da análise, da síntese e da exploração de ideias. Essas atividades concorrem para a construção do conhecimento e a apreensão dos saberes profissionais do futuro professor; entretanto podem se constituir em obstáculo para a aprendizagem imediata. É nesse sentido que abordamos, de forma mais específica, os pressupostos do letramento acadêmico.

0 ponto alto da investigação aqui proposta é que, de posse dos resultados, pretende-se oferecer contribuições para o redimensionamento dos princípios teóricos e procedimentos metodológicos que orientam e definem as atividades de ensino/aprendizagem da leitura e da escrita acadêmica na licenciatura em Letras. Os resultados da investigação poderão, ainda, oferecer indícios sobre possíveis alternativas para se enfrentar a questão do letramento acadêmico nos demais cursos de graduação. 
A abordagem metodológica foi qualitativa. Os instrumentos de coleta de dados foram: um questionário respondido por alunos e professores, entrevista com os professores que aplicaram a resenha e resenhas escritas por alunos do primeiro, terceiro, quinto e sétimo períodos do curso de Letras Português.

\section{Considerações teóricas}

Sabendo-se que as práticas de leitura e escrita são sociais e que delas emergem gêneros de acordo com as necessidades dos grupos com elas envolvidos, há que se considerar a existência de gêneros próprios de cada domínio discursivo. Nesse sentido, os saberes do domínio acadêmico são configurados por gêneros que compõem as práticas sociais desse contexto. Afinal, o contexto universitário é constituído por diversas práticas sociais, das quais emergem diversos gêneros.

Sendo assim, é possível afirmar que, ao conhecer as convenções que regulam as práticas de letramento na universidade, o aluno engaja-se nos modos de uso da escrita valorizados pelas diferentes disciplinas, variedade de áreas temáticas e diferentes situações comunicativas, considerando sua história prévia de letramento e seus valores identitários.

Sobre a aprendizagem de novas linguagens sociais e de diferentes gêneros, Gee (1996) afirma que é um processo que faz parte da socialização. Isso permite inferir que, ao aprender as convenções que regulam um determinado gênero, o estudante, na verdade, está aprendendo novos discursos que integram não só aspectos da língua escrita, mas também aspectos comportamentais, valores, crenças, sistemas simbólicos e tecnológicos, aprendizagens que ativam as identidades sociais dos indivíduos nas práticas sociais nas quais se inserem.

No que concerne à prática da escrita acadêmica, nosso entendimento é de que, anteriormente ao ingresso na universidade, os acadêmicos já percorreram uma trajetória de letramento e já adquiriram valores identitários. A partir daí, deve ocorrer a aprendizagem das convenções que regulam as novas práticas de letramento e o desenvolvimento das habilidades de leitura e de escrita específicas da esfera acadêmica, favorecendo o engajamento nos modos de uso da escrita valorizados pelas diferentes disciplinas e áreas temáticas da instituição.

Coadunamos com uma proposta (Klemp apud Fischer, 2007), que 
afirma que o letramento acadêmico pressupõe um desenvolvimento contínuo de conhecimentos sobre as diferentes formas de interação com os gêneros específicos desse domínio. Assim, tornar-se academicamente letrado implica, em sala de aula do ensino superior, durante toda a trajetória do curso, a utilização de estratégias eficazes que correspondam às diferentes demandas ou práticas sociais do contexto acadêmico.

Fica evidente que o letramento acadêmico diz respeito às "formas particulares de pensar, ser, fazer, ler e escrever, muitas das quais são peculiares a esse contexto social" (Fischer, 2008, p.180-181). Isso significa que um aprendiz academicamente letrado tem um repertório de estratégias efetivas para compreender e usar as diferentes, especializadas e contextualizadas linguagens do domínio acadêmico. Para tal, ele deve desenvolver um repertório de estratégias eficazes e fundamentais para a interação e apropriação dos diferentes gêneros que circulam nesse meio e para a constituição de uma identidade acadêmico-científica e profissional.

Diante desses posicionamentos, fica evidente que a concepção de letramento acadêmico, neste trabalho, é aquela estreitamente relacionada à concepção da escrita como ato social. Essa concepção pressupõe a familiaridade dos sujeitos com as diversas práticas discursivas letradas, especificamente, no que tange àleitura e escrita de textos teórico-científicos que pressupõem normalizações e são primordiais para o desenvolvimento profissional. Consideramos que as habilidades e competências para o letramento acadêmico devem ser desenvolvidas na universidade, durante o curso de graduação.

Importa salientar que, por gêneros acadêmicos, entendemos aqui, aqueles caracterizados, conforme restringe Maingueneau (2005), ora pelo domínio de produção e divulgação de saberes acadêmicos, tais como conferências, palestras, mesas-redondas, comunicações, teses etc., ora pelo suporte material específico, os periódicos acadêmicos especializados (resenha, artigo, ensaio, entrevista, relatório etc.) e, particularmente, as resenhas escritas por professores em formação no Curso de Letras Português.

Isso significa que escrever na academia é um fazer científico e que, para atender às condições de produção dos gêneros acadêmicos, é importante considerar que eles, como os demais, refletem não só suas condições específicas de produção, mas também suas finalidades, conteúdo temático, estilo, especificidades da linguagem como recursos lexicais e gramaticais, e, ainda, normas do texto científico. 
Conforme Schneuwly (2004), os gêneros são produzidos em uma determinada esfera de troca social e escolhidos em função da esfera, necessidades da temática, conjunto dos participantes e objetivos não só da esfera social como também do produtor. Sendo assim, conclui-se que as habilidades de leitura e de escrita de gêneros acadêmicos devem ser exercitadas por meio das experiências vivenciadas pelos acadêmicos, em contato com os aspectos culturais da comunidade discursiva, no caso a comunidade acadêmica.

Nessa mesma linha, para Dell'Isola (2007), a produção de gêneros, na esfera acadêmica, proporciona o diálogo, a interação, a retextualização e é, nesses movimentos de exercício de papéis sociais que ocorre a apresentação de conhecimentos, a avaliação de discursos e, consequentemente, o desenvolvimento das habilidades de leitura e escrita dos gêneros acadêmicos.

Devido à necessária estrutura composicional que caracteriza cada um dos gêneros, a escrita do gênero acadêmico exige o cumprimento de regras gerais que, sabe-se, não podem ser consideradas como algoritmos ou regras fixas, mas que estão momentaneamente estabilizadas, até haver alguma mudança por parte dos órgãos de normalização competentes.

Sobre isso, é importante ressaltar que, muito embora nem todos os textos pertencentes ao gênero acadêmico devam ser estruturados exatamente do mesmo modo, certos elementos são necessários, não só para o enquadramento em determinado gênero, mas também para que o propósito do gênero seja alcançado. Conforme Eggins (1994), a forma como um texto se organiza constitui sua 'estrutura esquemática' que, por sua vez, realiza o potencial do gênero a que pertence. Considerase, assim, que há elementos canônicos, obrigatórios, que facultarão o enquadramento de um texto em um gênero, e elementos opcionais.

Sendo assim, cabe ao professor universitário empreender reflexões acerca das habilidades que deseja auxiliar os alunos a desenvolver. Para tal, ele precisa deixar claros os objetivos das atividades e enfatizar o ensino por meio de um repertório de estratégias de comunicação, atuando como estimulador, crítico, encorajador, enfim, como mediador da aprendizagem.

Finalmente, é importante considerar que os textos que materializam gêneros acadêmicos asseguram o comprometimento do graduando com as práticas e papéis sociais da comunidade discursiva. São produções que apresentam uma linguagem com características diferenciadas e complexas para sua leitura, devendo sê-lo também para sua produção, além de 
exigirem que sejam desenvolvidas outras capacidades que extrapolam a mera organização das formas gramaticais do português padrão.

\section{Panorama do gênero resenha}

Para Maingueneau, um gênero encontra-se submetido a um conjunto de cinco condições de êxito: “a) uma finalidade reconhecida; b) o estatuto de parceiros legítimos; c) o lugar e o momento legítimos; d) um suporte material; e) uma organização textual" (Maingueneau, 2005, p.65-67). Naturalmente na produção do gênero resenha, essas condições variam em intensidade e ênfase, de acordo com os objetivos das diferentes esferas de produção e de divulgação, já que a resenha é um gênero que pode ser produzido em diferentes instâncias, e com objetivos também diferentes.

É assim que, na formação inicial dos professores, entendemos por resenha aquelas solicitadas pelos professores do curso de licenciatura em Letras Português, e em conformidade às respostas da Pergunta 1 Que importância você atribui à leitura e à escrita de textos acadêmicocientíficos? -, do questionário aplicado aos alunos e professores. Para os professores, "[resenhas] são necessárias para a formação profissional, pois promovem a aquisição de novos conhecimentos"; [...] "desenvolvem a capacidade linguística, o senso crítico e a autonomia de pensamentos e opiniões." E, para os alunos “[...] aprimoram e ampliam os conhecimentos, a cultura; aperfeiçoam a escrita e promovem a criticidade e a autonomia de pensamentos e opiniões, melhorando a formação" e “[...] proporcionam o saber científico para a pesquisa".

Logo, na esfera universitária, a resenha é uma oportunidade para que, ao mesmo tempo, os acadêmicos tenham acesso à aquisição de conhecimentos através de leituras e exercitem a produção de conhecimentos através da escrita. É o exercício de leitura e escrita que possibilita ao acadêmico o desenvolvimento de habilidades como descrever, argumentar, discutir, assumir posicionamentos acerca de textos e livros de sua área de estudo, provocar a reflexão e o diálogo com leituras realizadas durante a formação, assim, desenvolvendo a capacidade de atuar crítica e ativamente na comunidade acadêmica.

Assim sendo, ao se estabelecerem as condições de êxito para essas resenhas, é preciso estabelecer que sua finalidade primordial é a demonstração da capacidade de leitura compreensiva e escrita crítica- 
valorativa sobre o texto resenhado. Além disso, são também considerados outros fatores e valores relevantes evidenciados anteriormente por professores e alunos, assim como as respostas dadas pelos professores nas entrevistas realizadas para a verificação das condições de produção, momento no qual houve unanimidade de argumentação, quando afirmaram que o objetivo primeiro da solicitação de escrita da resenha é "motivar para a leitura do texto".

Sobre os interlocutores/enunciatários das resenhas acadêmicas, sabe-se que de um modo geral eles resenham por solicitação do professor e apenas para ele, já que não há, necessariamente, a obrigação de resenhar para divulgação da uma obra e nem de publicação das resenhas produzidas. Já quanto à organização textual, as resenhas devem apresentar características estruturais peculiares, conforme afirma Motta-Roth (2001), já que, caso contrário, enquadrar-se-iam em outro gênero. Contudo, isso não impede que as resenhas incluam, também, o cruzamento de outros interesses discursivos e papéis sociais.

Dessas considerações decorre o fato de que a escrita da resenha deve, obrigatoriamente, surgir do processo de retextualização, o que, necessariamente, implica mudança de propósito, vez que o sujeito opera com novos parâmetros de ação da linguagem. Para Matencio,

retextualizar, por sua vez, envolve a produção de um novo texto a partir de um ou mais textos-base, o que significa que o sujeito trabalha sobre as estratégias linguísticas, textuais e discursivas identificadas no texto-base para, então, projetá-las tendo em vista uma nova situação de interação, portanto um novo enquadre e um novo quadro de referência (Matencio, 2003, p.3-4).

Nessa mesma linha, ao abordar o tema retextualização, Marcuschi pondera que ela é um tipo de alteração marcada pela intervenção na estrutura de um texto, intervenção essa que, segundo ele, assume características diferentes conforme os objetivos que direcionam a nova produção e que estes, por sua vez, são dependentes dos sujeitos envolvidos no processo de retextualizar. Para corroborar essa afirmação, Marcuschi (2001, p.54) apresenta quatro variáveis fundamentais nos estudos dos processos de retextualização: "o propósito ou objetivo; a relação entre o produtor do texto original e o transformador; a relação tipológica entre 
o gênero textual original e o gênero da retextualização; e os processos de formulação típicos de cada modalidade" (Marchschi, 2001, p.54). Marcuschi afirma ainda que:

Atividades de retextualização são rotinas usuais altamente automatizadas, mas não mecânicas, que se apresentam como ações aparentemente nãoproblemáticas, já que lidamos com elas o tempo todo nas sucessivas reformulações dos mesmos textos numa intrincada variação de registros, gêneros textuais, níveis linguísticos e estilos (Marcuschi, 2001, p.48).

Essas considerações permitem afirmar que, neste trabalho, a resenha no curso de Licenciatura é uma atividade de retextualização, entendida como ação de dar origem a um novo gênero (resenha) na modalidade escrita, a partir de outro texto também na modalidade escrita (livro, capítulo de livro, artigo, sempre de natureza teórica ou literária), mantendo a base informacional desse texto, como propõem Marcuschi (2008) e Dell'Isola (2007).

Sendo assim, a atividade de resenhar na academia é estreitamente relacionada com o funcionamento social da linguagem e deve ser executada conforme os propósitos ou objetivos de cada professor que a solicita. Implica a mudança de gênero e dos processos de formulação típicos da modalidade e resulta em uma produção normalmente bem mais extensa do que as resenhas da esfera jornalística que são escritas com a finalidade de publicação e divulgação de obras.

Como em qualquer produção textual escrita, a resenha requer, além da necessária organização estrutural, o exercício de práticas discursivas de leitura e de escrita. Essas atividades são constantemente solicitadas aos acadêmicos, já que operações textual-discursivas, com características semelhantes à resenha, são também encontradas na fundamentação teórica de relatos de experiências, em artigos, monografias, dissertações, teses, prefácios, apresentações de livros, ensaios e outros pertinentes a essa área de estudos e que requerem não só leitura compreensiva, mas também, um posicionamento crítico e valorativo fundamentado.

Nesse sentido, conforme afirma Motta-Roth (1996), resenhar é uma oportunidade para que os escritores inexperientes - no caso, os graduandos - sejam iniciados no debate acadêmico. Já para Bazerman (2006), sendo um agente que participa da estruturação comunicativa acadêmica, 
ao ler ou produzir resenhas, o aluno formaliza seu papel de aprendiz na universidade. Sobre isso, Silva, Assis e Matencio assim se pronunciam:

investir em atividades de retextualização na formação do professor concorre para sua inserção em práticas discursivas do âmbito acadêmico, porque lhe permite, de forma sistematizada, ter acesso a modos de textualização dos saberes (um saber dizer) e apropriar-se de conceitos e procedimentos acadêmico-científicos (um saber fazer) (Silva; Assis; Matencio, 2001, p.1).

Fica evidente que a escrita de resenhas na universidade é uma forma de inserção do acadêmico nas atividades de leitor para aquisição e produção de saberes, o que requer que o aluno exercite e comprove suas habilidades de sujeito letrado. Por envolver tanto a apropriação e sistematização dos saberes científicos, quanto a construção de conhecimentos, a resenha constitui uma estratégia para a complementação da formação docente.

Matencio e Silva (2003), ao fazerem referência à produção de resenhas em contextos de ensino, afirmam que as condições reguladoras são diferentes daquelas em que estão envolvidos os especialistas. Nesse sentido, elas assim se posicionam sobre a resenha no contexto das ações de ensino/aprendizagem:

configura-se como objeto de estudo de crucial importância, por definir-se, a um só tempo, como uma atividade através da qual o aluno pode, de forma sistemática, apropriar-se tanto de saberes relativos ao funcionamento e à configuração textual do gênero como de conceitos e procedimentos teóricos e metodológicos envolvidos na área de conhecimento em estudo (Matencio; Silva, 2003, p.3).

0 resenhista precisa, então, considerar que o contexto é fonte de sentido e ponderar que o entendimento e a produção dependem, em parte, da esfera discursiva na qual o texto é produzido. Entendendo isso, como leitor, o resenhista dá novo significado ao lido e produz, de modo a demonstrar conhecimentos e atender às exigências do contexto de produção. Nesses movimentos, demonstra seu grau de letramento, o que é, certamente, desafiador para o acadêmico iniciante. 
Vale enfatizarque os gênerostextuais são produzidoscom finalidades discursivas específicas e que, para cumprir suas especificidades, cada um deles conta com uma estruturação própria e com recursos de linguagem também específicos. Deve-se contemplar as operações de linguagem que evidenciam o posicionamento enunciativo do resenhista, no que se refere, por exemplo, ao gerenciamento de vozes, responsável pela coerência pragmática e interativa.

\section{Operações de linguagem}

Por operações de linguagem, vale salientar, reportamos aqui àquelas utilizadas pelo autor de um texto e que, conforme Bronckart (2012) são frutos do trabalho social e semiótico de gerações anteriores e estão disponíveis na forma de regras. Para o autor, “[...] essas regras, cristalizadas na intertextualidade de uma língua natural, exercem uma restrição decisiva sobre as operações realizadas na produção de um texto regular" (Bronckart, 2012, p.324), já que definem possibilidades restritas às quais o autor se submete. Isso implica que, ao produzir o seu texto a partir de outro, o resenhador estabelece uma dialogicidade. Ele utiliza estratégias não só para manter-se presente por meio da sua própria voz, mas também para inserir o discurso de outros, movimentos realizados por meio da inserção de marcas da voz do autor resenhado e dos demais autores aos quais ele eventualmente.

Sendo assim, o autor da resenha precisa estabelecer claramente os limites entre as ideias do autor do texto objeto da resenha e as suas próprias ideias. Boch e Grossmann (2002) criam critérios de diferenciação dos modos de referir-se ao discurso do outro, aqui reproduzidos no quadro a seguir. 
Quadro 1 - Critérios que permitem diferenciar os modos de referência ao discurso do outro

\begin{tabular}{|l|l|l|}
\hline \multicolumn{1}{|c|}{ Evocação } & \multicolumn{1}{|c|}{ Reformulação } & \multicolumn{1}{|c|}{ Citação } \\
\hline $\begin{array}{l}\text { Ausência de marcas introdutórias } \\
\text { de discurso reportado (tais como: } \\
\text { segundo X, como afirma X, ou } \\
\text { equivalentes). }\end{array}$ & $\begin{array}{l}\text { Presença de marcas introdutórias do discurso } \\
\text { reportado (segundo X..., de acordo com X...,para } \\
\text { X..., como Xafirma...,como X pretende..., etc.). }\end{array}$ & $\begin{array}{l}\text { Marcas, geralmente escriturais, como aspas, } \\
\text { itálico ou bloco tipográfico, permitem } \\
\text { identificar um segmento do texto como } \\
\text { extraído de uma fonte externa; essas marcas } \\
\text { temático do dizer do outro. }\end{array}$ \\
$\begin{array}{l}\text { Presença de um nome próprio de } \\
\text { autor, frequentemente com data à vezes, ser substituídas por } \\
\text { qual o autor do artigo se refere, sem } \\
\text { precisar o teor do texto. }\end{array}$ & $\begin{array}{l}\text { Ausência de marcas escriturais tais como } \\
\text { aspas (ou verbais, como eu cito X, para } \\
\text { retomar as palavras de X). }\end{array}$ & $\begin{array}{l}\text { comentários metalinguísticos: eu cito X..., para } \\
\text { retomaras palavras de X...); } \\
\text { enunciativa. }\end{array}$ \\
\hline
\end{tabular}


Esses entendimentos nos levam a afirmar que, para fins da análise aqui proposta, a evocação, a reformulação e a citação representam recursos que comportam, também, e fundamentalmente, uma dimensão enunciativa. Nela entra em jogo o posicionamento dos interlocutores, indo além, portanto, do que é delineado nos manuais de metodologia científica que, por si só, não são suficientes para tornar os acadêmicos competentes na escrita desse gênero, e, consequentemente, academicamente letrados.

\section{Sistematizando a análise}

De posse das produções, procedemos, inicialmente, ao que chamamos de uma análise textual: leitura atenta para uma visão do conjunto e visualização da estrutura redacional. A seguir, realizamos uma análise temática: leitura com vistas a identificar linha de raciocínio seguida para reconstrução do processo lógico do pensamento do autor, assim como para identificar a compreensão do tema, da ideia central e das ideias secundárias. Finalmente, uma análise interpretativa: leitura para percepção dos detalhes evidenciados como referenciação e contextualização da obra e do autor, percepção dos pressupostos teóricos e filosóficos, relacionamento das ideias do autor com outros autores e com seu próprio entendimento como autor, explicitação do juízo pessoal: avaliação e valoração, etc. Vale enfatizar que, paralelamente à leitura das produções, foi feita a leitura dos textos que deram origem a elas.

Realizadas essas ações, foi possível organizar as produções em quatro blocos distintos, conforme suas especificidades: cópias, resumos, resenhas e outros. Os percentuais de cada turma estão evidenciados no Quadro 2:

Quadro 2: Percentual dos gêneros

\begin{tabular}{|l|c|c|c|c|}
\hline \multirow{2}{*}{ PRODUÇÕES } & 1을 & 3 PER & 5 PER & 7 PER \\
\cline { 2 - 5 } & $\%$ & $\%$ & $\%$ & $\%$ \\
\hline Cópias & 25 & - & 16 & 20 \\
\hline Resumos & 75 & - & 56 & 60 \\
\hline Resenhas & - & 100 & 24 & 20 \\
\hline Outros & - & - & 4 & - \\
\hline TOTAL DE PRODUÇÕES & 20 & 12 & 25 & 10 \\
\hline
\end{tabular}

Fonte: Elaborado pela autora com base nas produções 
Conforme o quadro, os acadêmicos do primeiro período não produziram resenhas, mas cópias e resumos. Esse fato não causa surpresa, porque o estudo da resenha não é contemplado nos anos de escolarização que antecedem o ensino superior. Nas respostas dadas à pergunta seis do questionário, $100 \%$ dos alunos desse período declararam não ter, ainda, escrito resenhas durante o curso.

\section{Movimentos de linguagem: gerenciamento de vozes}

Conforme os critérios que permitem diferenciar os modos de referência ao discurso do outro, conforme Boch e Grossmann (2002), apresentados no Quadro 1, a análise qualitativa das resenhas nos permitiu a verificação da presença de evocação em apenas uma resenha. Quanto ao discurso reportado, detectamos a presença de reformulação em todas as resenhas, de citação em apenas sete e de ilhota citacional em cinco.

\section{Evocação}

Normalmente caracterizada pela presença do nome próprio do autor do texto-base, frequentemente seguido da data da obra citada, sem, contudo, precisar o teor do texto, a evocação apareceu apenas no parágrafo 11 da PROD 2 (3ํㅜ), mas sem as datas da publicação das obras.

RES 2 - 3ㅇ $\mathrm{P}$

§ 11- O Estruturalismo influenciou muito aqui no Brasil. Um dos estudiosos é Joaquim Matoso Câmara Junior que adotou concepções do Estruturalismo Europeu e Americano. Em São Paulo na década de 1960 alguns professores bolsistas recém-chegados da França adotam as leituras de André Martinet, Bernard Pottier, Barthes, Algirdas J. Greimas, além de Saussure.

O fato de ter sido utilizado apenas uma vez e em uma única resenha nos leva a concluir que os alunos têm dificuldade para lidar com esse gerenciamento. Vale salientar que resultados semelhantes foram apresentados em pesquisa realizada por Boch e Grossmann (2002). Eles verificaram a presença da evocação apenas em textos de especialistas, quando comparados a textos de estudantes de letras. 


\section{Reformulação}

Caracterizada pela presença de marcas introdutórias do discurso reportado, sem marcação de aspas ou outro recurso, em que o discurso do outro é integrado no discurso de quem escreve, a reformulação foi, sem dúvida, o modo de referência ao discurso do outro privilegiado pelos acadêmicos na escrita das resenhas analisadas. Provavelmente, isso ocorreu pelo fato de ela ser reconhecida como procedimento não só econômico, mas também facilitador do gerenciamento da voz enunciativa. 0 discurso do autor do texto resenhado foi integrado ao discurso do acadêmico autor da resenha, preservando-se a autonomia daquele, e circunscrevendo, dessa forma, a alteridade enunciativa.

Exemplos de reformulação foram verificados em todas as resenhas de todos os períodos, conforme ilustram os fragmentos abaixo:

PROD 5 - 3ㅇ P

$\S 2$ - $O$ autor aborda neste texto que o estruturalismo teve [...].

$\S 5$ - Segundo Rodolfo a escola [...]. Luis Hjelmsleu valorizou as relações entre as unidades de [...].

PROD $8-3^{\circ} \mathrm{P}$

§ 1- 0 autor descreve a importância do Estruturalismo que teve impacto no Brasil durante os anos de 1960 [...].

$\S 3$ - Segundo Saussure o significado e o significante não teve sua existência relacionados a fatores [...].

PROD 1 - 5ㅇ $\mathrm{P}$

§ 6- No último tópico do capítulo, as autoras descrevem o processo de observação direta extensiva, [...].

PROD $3-5^{\circ} \mathrm{P}$

§3- As autoras explicitam características da Pesquisa Documental [...].

PROD 1 - 7으 $\mathrm{P}$

$\S 1$ - $O$ autor começa seu texto discorrendo sobre [...]. Nunes continua dizendo $[\ldots]$.

$\S 7$ - Para Nunes, o ideal do Manifesto da Poesia [...]. 
Curiosamente raríssimas vezes o acadêmico reformula o discurso do outro, utilizando a forma nome do autor seguido da data de publicação entre parênteses. Entendemos que essa é apenas uma dificuldade técnica que pode ser superada com a interferência do professor, durante o processo de retextualização.

Com o objetivo de ilustrar a reformulação em uma resenha completa, segue a PROD 6:

PROD 6 - 5 $\mathrm{P}$

§ 1- No capítulo 9, do livro Metodologia Científica, Lakatos (2003) e MARCONI (2003), fazem uma abordagem sobre as técnicas de pesquisas essenciais à qualquer ciência.

§ 2-Segundo os autores, as técnicas de pequisas são habilidades para a obtençao de propósitos. [...]. Dessa forma esta pesquisa documental pode ser feita [...]. [...] nesse viés, vem enfatizar também os documentos escritos [...].

$\S 3$ - Depois de fazer uma abordagem da pesquisa documental, os autores relatam sobre a pesquisa bibliográfica [...]. Assim, tem-se fontes de documentos diferentes que requerem procedimentos diferentes, [...]. Este tipo de procedimento requer procedimentos [...].

$\S 4$ - Depois dessa abordagem, Marconi e Lakatos falam sobre a documentação direta que é [...]., e assim pode-se distinguí-la de duas formas: pesquisa de campo e de laboratório.

$\S 5$ - Em consonância com o assunto, os autores ressaltam que a pesquisa de campo está relacionada a observação dos fatos, ou fazer a coleta de dados de determinado fenômeno, mas de forma completa, [...].

§ 6 - Os autores abordam também que a observação direta intensiva pode ser realizada através de duas técnicas: a de observação e de entrevista.

$\S 7$ - [...]. Neste mesmo parâmetro, percebe-se que esta se divide em dois tipos: [...]. Nesta observação sistemática há o que se observar também [...]. 
§ 8 - Depois dessa abordagem da observação, Marconi e Lakatos abordam a questão da entrevista, que segundo estes, consistirá em um encontro entre duas pessoas para se obter informações a respeito de um determinado assunto. Dessa forma, haverá procedimentos de investigação social para a coleta de dados. Nesse âmbito, os autores expõem os objetivos da entrevista, [...].

$\S 9-$ Por fim, os autores ressaltam a questão do questionário [...]. $\S 10$ - Os autores abordaram o assunto de metodologia científica de forma bastante [...].

$\S 11$ - Todos estes aspectos abordados no texto são muito interessantes já que ensinam ao estudante a não perder o foco de sua pesquisa, pois seguindo tais aspectos, pode-se obter um estudo mais interativo [...].

Conforme está explícito nessa resenha, o aluno, ao longo de sua escrita, busca dar ao leitor uma visão geral, porém, esquemática e sequencial do assunto resenhado. Ele faz isso por meio de recursos coesivos que remetem àqueles que se apresentam no material resenhado e que permitem entrever seu posicionamento enunciativo. Para tal ele utiliza as expressões "Dessa forma [...]" e “[...] nesse viés [...]", no parágrafo 2; "Assim [...]" e "Este tipo de procedimento [...]", no parágrafo 3; “Depois dessa abordagem [...]" e "[...] e assim [...]", no parágrafo 4, "Em consonância [...]", no parágrafo 5; "[...] abordam também [...]", no parágrafo 6; "Percebe-se que [...]" e "Nesta observação [...]", no parágrafo 7; "Depois dessa abordagem [...]", “[...] segundo estes [...]" e "Nesse âmbito [...]", no parágrafo 8; e a expressão "Por fim [...]", no parágrafo 9.

A inserção do discurso do outro é feita por meio do discurso reportado utilizando, como recurso, as expressões introdutórias: "Lakatos (2003) e Marconi (2003), faz uma abordagem [...]", "Segundo os autores [...]”, “[...] os autores relatam [...]”, “[...] Marconi e Lakatos falam [...]”, “[...] os autores ressaltam [...]", "Os autores abordam também [...]", "Marconi e Lakatos abordam [...]", “[...] os autores ressaltam [...]", "Os autores abordaram [...]". Desse modo, o autor da resenha mostra que se apoia no autor do texto resenhado. Como não se constrói, no caso em questão, tipo algum de oposição ao que é trazido, pode-se entender que, por meio dos expedientes citados, a resenhista sinaliza que não só coaduna com esse autor, como também adere às ideias por ele explicitadas, além de conferir- 
lhe autoridade. Conforme afirma Maingueneau (2002), essa é também uma forma de criar autenticidade e tornar-se objetivo e sério.

Essas expressões que introduzem o procedimento de reformulação, de querer dizer com as próprias palavras o que o outro disse, proporcionam uma aproximação do ato de pensar, de expressar uma compreensão própria do lido, favorecendo a manifestação de atitudes reflexivas e conscientes, em detrimento do mero exercício de reprodução fiel do dizer do outro.

Com referência ao modo como os estudantes fazem a introdução do discurso do outro, na resenha ilustrativa anterior e nas demais que constituem nosso corpus, nota-se que há uma predileção pelo discurso indireto, em que, conforme Authier-Revuz (2004), o locutor traduz, usando suas próprias palavras, o dizer do outro, remetendo ao outro como fonte do sentido dos propósitos que relata.

Tais expedientes se dão com o uso de verbos dicendi ou do dizer (normalmente utilizados para reportar falas de outras pessoas); no caso das resenhas, o resenhista incorpora à sua a linguagem do autor do texto resenhado, de modo a evidenciar apenas a essência do pensamento deste autor.

De modo geral, os termos introdutores do discurso reportado, nos dados examinados neste trabalho, apareceram no início de parágrafos ou de períodos, iniciados mais comumente com expressões do tipo "o autor [...]" ou com o próprio nome do autor, e, em ambos os casos, seguidos do verbo. Ocorreram, também, na forma de referência pronominal, na forma de elipse (aqui indicada pelo símbolo Ø) em que é possível resgatar o nome do autor anaforicamente com em "Saussure buscou [...], ele utiliza o jogo [...]. Ø utiliza o jogo para contrapor [...]". Os alunos recorrem, ainda, a expressões adverbiais e a termos que remetem à obra resenhada como formas de introdução do discurso reportado. Exemplos podem ser verificados no quadro 3 : 
Quadro 3: Termos introdutórios do discurso reportado

\begin{tabular}{|c|c|}
\hline Tipos & Exemplos \\
\hline \multirow{6}{*}{$\begin{array}{l}\text { Iniciadas com a } \\
\text { expressão "o autor", ou } \\
\text { com o próprio nome } \\
\text { do autor, seguidos do } \\
\text { verbo. }\end{array}$} & $O$ autor inicia seu texto \\
\hline & Hjelmslev explicita essa distinção \\
\hline & Os autores trazem \\
\hline & $O$ autor aborda no texto o... $\varnothing$ Faz-se referência \\
\hline & Rodolfo Ilari trata \\
\hline & $\begin{array}{l}\text { Saussure buscou..., ele utiliza o jogo,... } \varnothing \text { Utiliza o jogo } \\
\text { para "contrapor" }\end{array}$ \\
\hline \multirow{2}{*}{$\begin{array}{l}\text { Iniciadas com } \\
\text { expressões adverbiais }\end{array}$} & Segundo Rodolfo [...]. \\
\hline & De acordo com Nunes, [...]. \\
\hline \multirow{11}{*}{$\begin{array}{l}\text { Iniciadas com termos } \\
\text { que remetem à obra } \\
\text { ou a partes dela, } \\
\text { seguidos de verbo. }\end{array}$} & O primeiro capítulo [...] retrata [...]. \\
\hline & O capítulo em questão termina destacando [...]. \\
\hline & O sexto e último capítulo da obra diz respeito [...]. \\
\hline & O presente capítulo II aborda [...]. \\
\hline & O oitavo tópico intitulado [...] trás [...]. \\
\hline & A outra parte do texto vai tratar [...]. \\
\hline & A linguística estrutural também trouxe [...]. \\
\hline & No tópico 9.12, inicia-se a [...]. \\
\hline & No segundo tópico do capítulo IX, trata-se de [...]. \\
\hline & O texto: aborda [...]. \\
\hline & Essa obra: tem grande valor, [...]. \\
\hline
\end{tabular}

Fonte: Elaborado pela autora.

Como é possível notar, há passagens em que são usadas expressões adverbiais, introduzindo um discurso quase sempre parafraseado e, muito raramente, com a tentativa de citação literal. Essas marcas também garantem a responsabilidade pelo dito ao próprio autor do texto resenhado, contando, evidentemente, com o respaldo do autor da resenha, na medida em que este é que traz o dizer de outrem. 
Ocorreu, também, certo ocultamento da voz do autor resenhado, por meio de recursos em que a origem do dito é atribuída ao próprio livro, capítulo ou às suas partes. Com as expressões indicativas de partes da obra (capítulo, tópico), ou mesmo de partes do assunto (A linguística estrutural [...]), seguidos dos verbos na terceira pessoa do singular acompanhados ou não do pronome "se", o resenhista mantém uma impessoalidade em relação ao dito, colocando-se à distância.

Ainda com relação aos recursos de introdução ao discurso do outro, é interessante salientar que, nas vinte produções classificadas como resenhas, ocorreram 75 verbos diferentes, dos quais 43 foram utilizados apenas uma vez. Os alunos elegeram como preferidos os verbos "abordar", no sentido de falar sobre (14 vezes) e "ressaltar", no sentido de pôr em evidência ( 9 vezes). Os demais aparecerem em uma pequena quantidade de vezes, sendo a maioria deles (43), apenas uma vez.

Pode-se dizer que tais verbos revelam uma atitude interpretativa do resenhista, em relação ao que se retextualiza. Além disso, são verbos que indicam, de algum modo, o efeito (perlocucional) que o autor da resenha queria provocar no destinatário, ou seja, um efeito responsivo, como um convite ao compartilhamento com ele da tarefa de levar adiante as ideias apresentadas. Ao mesmo tempo, ele se exime de assumir, por sua conta, a responsabilidade enunciativa e o que realiza é um trabalho interpretativo, atribuindo ação, acontecimento, atividade mental etc., ao autor do texto resenhado.

\section{Citação}

Esse recurso de linguagem é visto como uma estratégia discursiva que reporta à voz do autor do texto resenhado (como autoridade), criando um efeito de realidade, de modo a dar a impressão de que a instância geral da enunciação apenas repete o que diz a voz reportada. Dessa forma, a citação cria um espaço autônomo no plano enunciativo. Conforme esclarecem Boch e Grossmann (2002), marcas, geralmente escriturais, como aspas, itálico ou bloco tipográfico, permitem identificar um segmento do texto como extraído de uma fonte externa. Essas marcas podem, às vezes, ser substituídas por comentários metalinguísticos do tipo “Cito X [..], para retomaras palavras de X [...]", recursos não utilizados nas resenhas analisadas. 
A citação deve, conforme afirmam Boch e Grossmann (2002, p.107), ser compreendida, “[...] como gesto paradoxal de inserção de um discurso que é, quase sempre, radicalmente outro (em seu vocabulário, em seu estilo, pelos espaços teóricos que abre), dentro de um discurso tateante, às vezes disforme, mas no qual eles aprendem a se constituir como sujeitos".

Nesses termos e conforme já explicitado, é desejável que a citação seja utilizada como uma forma de apoio à construção enunciativa do resenhista, processo que nem sempre ocorreu, de forma satisfatória, nas resenhas analisadas. Por exemplo, nos parágrafos transcritos abaixo, as passagens identificadas como modos de referir-se ao discurso do outro estão em negrito e, por seu intermédio, o resenhista insere citações.

\section{PROD 2 - 5o P}

§ 2- As autoras apontam a importância da técnica em um estudo e a define: "Técnica é um conjunto de preceitos de que se serve uma ciência ou arte; é a habilidade para usar esses preceitos ou normas, a parte prática. Toda ciência utiliza inúmeras técnicas na obtenção de seus propósitos". (Lakatos; Marconi, 2003, p.174).

§ 7- Em seguida é apresentada a parte bibliográfica da pesquisa. "Da mesma forma que as fontes de documentos, as bibliográficas variam, fornecendo ao pesquisador, diversos dados e exigindo manipulação e procedimentos diferentes". (Lakatos; Marconi, 2003, p.183).

PROD $5-50 P$

§ 8- [...]. Com referência à Bateria, a autora afirma que "é uma série de perguntas que têm a finalidade de aprofundar algum ponto importante da investigação e do questionário ou formulário.".

§9- Lakatos também cita três qualidades essenciais de todo formulário, apontadas por Ander-Egg (1978:125): "Adaptação ao objeto de investigação; adaptação aos meios que se possui para realizar o trabalho; precisão das informações em um grau de exatidão suficiente e satisfatório para o objetivo proposto".

Por meio das citações, o resenhista apoia-se no dizer do outro, de forma acriar um espaço autônomo no plano enunciativo. Há, nesses casos, uma reprodução fiel de trechos com falhas em detalhes da técnica normativa de citação, que podem ser sanados com pesquisas e discussões metodológicas.

Conforme Boch e Grossmann (2002), a citação aparece nas produções acadêmicas como palavras emprestadas favorecedoras da 
assunção da própria voz, das próprias escolhas, implicando o exercício das habilidades de dialogar com o autor e com o texto/assunto para, desse modo, demonstrar a capacidade crítica e ativa de leitor e produtor de textos, refletindo, evidentemente, seu grau de letramento.

Na PROD 3 (5ํㅜ), o aluno tenta fazer citação autônoma:

\begin{tabular}{|c|c|}
\hline PROD 3 (5ㅇ) & LAKATOS e MARCONI (2003, p.213) \\
\hline $\begin{array}{l}\S 21 \text { - Na } \\
\text { última página } \\
\text { do capítulo } \\
\text { IX, alguns } \\
\text { aspectos para } \\
\text { a apresentação } \\
\text { do formulário } \\
\text { como o tipo, } \\
\text { o tamanho, } \\
\text { deve ser } \\
\text { datilografado, } \\
\text { mimeografado } \\
\text { ou impresso em } \\
\text { uma só face do } \\
\text { papel, uma vez } \\
\text { que “causam } \\
\text { má impressão, } \\
\text { formulários } \\
\text { antiestéticos", } \\
\text { de acordo com } \\
\text { Witt (1973:46). }\end{array}$ & $\begin{array}{l}\text { A observância de alguns aspectos é necessária na } \\
\text { construção do formulário, para facilitar o seu manuseio e } \\
\text { sua posterior tabulação. } \\
\text { Deve ser levado em conta o tipo, o tamanho e o formato do } \\
\text { papel; a estética e o espaçamento devem ser observados } \\
\text { e cada item deve ter espaço suficiente para a redação das } \\
\text { respostas. Os itens e subitens precisam ser indicados com } \\
\text { letras ou números e as perguntas ter certa disposição, } \\
\text { conservando distância razoável entre si. Deve ser } \\
\text { datilografado, mimeografado ou impresso em uma só face } \\
\text { do papel. É importante numerar as folhas. } \\
\text { As formas de registro [...]. } \\
\text { A redação simples, clara, concisa é ideal. Itens em } \\
\text { demasia devem ser evitados. "Causam má impressão } \\
\text { questionários ou formulários antiestéticos em termos de } \\
\text { papel, disposição das perguntas, grafia etc.", afirma Witt } \\
\text { (1973: 46). }\end{array}$ \\
\hline
\end{tabular}

Ao comparar o excerto da PROD 3 (5ํㅜ) com fragmentos do textobase, nota-se que falta um critério para a escolha do que deve ser citado. As lacunas deixadas pelo acadêmico prejudicam a compreensão do escrito e demonstram que a leitura não foi bem-feita. Ele apenas condensa partes do texto que deu origem à resenha. Em seu parágrafo, ele não assegura os aspectos que causam má impressão. Além disso, ao fazer referência quanto ao tipo e ao tamanho, ele não assegura os demais itens abarcados por Witt. Ademais, o correto seria dizer (Witt apud Lakatos; Marconi, 2003, p.213), já que é uma citação de citação, caracterizando a inserção de uma voz que não é a do autor do texto resenhado, conforme ensinado na disciplina Metodologia da Pesquisa Científica, ministrada no $1^{\circ}$ período. 


\section{Ilhota citacional}

Por meio desse recurso, o aluno ressalva a referência ao discurso reportado, destacando-o com aspas, mas integra seu ponto de vista ao do autor. Exemplos podem ser vistos destacados nos fragmentos a seguir:

PROD 9 - 3우

§ 4- A língua [...] já a fala é a língua posta em ação, e por ser um ato individual faz alusão aos possíveis usos do sistema, isto é, da língua, essa distinção chega-se a mais fundamental das oposições saussurianas conhecidas como "oposição língua/fala" ou "oposição langue/parole,"[...].

§9- O Funcionalismo orientou a França nos anos anteriores ao Estruturalismo, e contribuiu para que a França se identificasse com tal corrente, reafirmando a "dupla articulação da linguagem - estabelecendo que haveria em toda língua natural dois níveis de oposição" (p.72), [...].

§ 12- [...] foi escolhida apenas uma variedade de tantas outras como padrão devido aspectos de classe social e estética, dando atenção também aos fatos falados, representando um avanço em relação ao Estruturalismo, todavia, "não seriam possíveis sem ele" (p.89).

PROD 2 - 7으

§7-O ideal do manifesto Pau-Brasil é harmonizar duas pontes não antagônicas, a cultura nativa e a intelectual renovada; "o melhor de nossa tradição lírica com o melhor de nossa demonstração moderna". Em fim, Nunes encerra essa primeira parte fazendo apologia à visão poética Pau-Brasil e ao Pensamento Selvagem os quais estão associados às correntes de vanguarda oswaldiana.

De um modo geral, constatou-se a escassez do discurso reportado, seja por meio de reformulação, citação ou ilhota citacional e, é comum a ocorrência de falhas no modo como os acadêmicos utilizam esses recursos. Entendemos que esses fatores refletem a falta de habilidade para empreender o processo de retextualização, e são fortes indicativos de que os acadêmicos ainda não alcançaram um grau elevado de letramento acadêmico.

\section{Considerações finais}

A análise das produções possibilitou-nos a compreensão de que são visíveis as dificuldades dos acadêmicos na escrita do gênero resenha. Em primeiro lugar, a dificuldade é referente ao desafio de compreender a 
natureza do gênero e não de redigir um resumo ou simplesmente recorrer a ações de cópia, já que apenas $29,85 \%$ das produções puderam ser enquadradas como resenhas.

Em segundo lugar, verificamos que há problemas no estabelecimento dos limites de um posicionamento autoral consistente, levado a termo por meio do emprego dos mecanismos enunciativos que contribuem para a coerência pragmática da produção. Nem todos os acadêmicos apresentaram, com segurança, o domínio do gerenciamento de vozes necessário à indicação do posicionamento autoral do resenhista, de forma a estabelecer limites claros entre suas ideias, as do autor do texto resenhado e as de outros autores cujas vozes se entrecruzam nesse texto.

Entendemos que, quando se limitam a reproduzir as vozes já ditas pelo autor do texto resenhado ou de outros por ele citados, os acadêmicos demonstram a necessidade de um redimensionamento das práticas de ensino do texto acadêmico no curso em que os dados foram coletados. Necessário se faz a assunção de um compromisso sistemático não só com as questões estruturais, mas, sobretudo, com as práticas de linguagem precisamente no que se refere ao gerenciamento de vozes peculiar ao gênero.

Concluímos que o trabalho do professor com o ensino/aprendizagem da leitura e produção de textos acadêmicos, visando ao letramento acadêmico seria mais bem desenvolvido sob a perspectiva do Interacionismo Sócio-discursivo. Essa teoria considera o texto como a materialização de uma ação constituída por uma série de operações de linguagem que, necessariamente, devem ser vistas pelos agentes da prática de formação universitária como um conjunto de operações que envolvem a linguagem, constituindo uma unidade, cuja responsabilidade de realização é atribuída ao indivíduo. Este, por sua vez, é movido por motivos e orientado por objetivos, no momento de interlocução social.

No âmbito de um curso de licenciatura, o objetivo do professor deve, assim, ser o de proporcionar ao acadêmico o domínio dessas operações de linguagem para que ele possa desenvolver a capacidade necessária para agir. Tendo em vista que essas ações, operações e capacidades não são inatas, cabe ao professor colaborar para que seu aprendizado ocorra.

Consideramos que a atividade de escrita de resenhas é uma oportunidade para o contato com as diferentes operações de linguagem que, certamente, influenciarão na leitura e produção dos demais textos da es- 
fera acadêmica. Desse modo, é uma atividade que conduzirá o aluno da graduação ao letramento acadêmico.

Somos de parecer que, mais do que ensinar sistematicamente a estrutura do gênero resenha, e certamente de outros gêneros do domínio acadêmico, é importante, e necessário, no ensino superior, a discussão sobre os recursos de linguagem exigidos para a produção desses gêneros. 0 gerenciamento de vozes, por exemplo, é tão importante para o processo de ensino e aprendizagem da leitura quanto para o ensino e aprendizagem da produção de textos, uma vez que proporciona ao aluno a oportunidade de ser o autor de seu próprio texto e agente da ação da linguagem. Consideramos que é no eficiente trabalho com a linguagem que é possível desenvolver a identidade acadêmica, de forma a proporcionar a competentização para o enfrentamento das situações que são requeridas a um sujeito academicamente letrado.

Com essa orientação, possibilitar-se-á ao estudante decidir sobre o conteúdo temático a ser semiotizado, escolher um modelo de gênero adaptado à sua situação de comunicação, selecionar e organizar os tipos de discursos, bem como gerenciar os diversos mecanismos de textualização. Se assim for, se tornará responsável pelo que escreve e passará a ser agente da linguagem, autor do seu texto, e, academicamente letrado.

Como a investigação não é exaustiva, sugerimos que outras pesquisas referentes à produção de textos e ao letramento acadêmico sejam desenvolvidas no âmbito do curso. Somos de parecer que, se os alunos da graduação apresentam dificuldades para inserir as vozes na resenha, ao relatarem o discurso do outro, dificuldade igual devem sentir para redigir os demais gêneros acadêmicos.

\section{Referências}

ASSIS, Juliana Alves; MATA, Maria Aparecida da. PERINI-SANTOS, Pedro. Ensino aprendizagem de resumos acadêmicos em sala de aula: negociação de representações. In: ENCONTRO INTERNACIONAL DE LINGUAGEM, CULTURA E COGNIÇÃO: REFLEXÕES PARA O ENSINO, 2, Campinas, SP: Anais, Graf. FE ALB, 2003.

BAKHTIN, M. Marxismo e filosofia da linguagem. São Paulo: Hucitec, 1997.

BARTON, D. Literacy: an Introduction to the ecology of written language. London: Blackwell, 1994

BARTON, D.; HAMILTON, M. Local literacy: reading and writing in one community. London and New York: Routledge, 2000. 
BOCH, Françoise; GROSSMANN, Francis. Referir-se ao discurso do outro: alguns elementos de comparação entre especialistas e principiantes. Trad. Maria de Lourdes Meirelles Matencio. Scripta, Belo Horizonte, v.6, n.11, p.97-108, 2º sem. 2002.

BRONCKART, Jean-Paul. Atividades de linguagem, textos e discursos: por um interacionismo sociodiscursivo. Tradução de Anna Rachel Machado e Péricles Cunha. 2ed. São Paulo: EDUC, 2012.

DELCAMBRE, Isabelle; JOVENET, Anne-Marie. Lire-écrire dans le supérieur. Spirale, n.29, 2002.

DELL'ISOLA, R. L. P. Retextualização de gêneros escritos. Rio de Janeiro: Lucerna, 2007.

EGGINS, Suzanne. An introduction to systemic functional linguistics. London: Pinter, 1994.

FISCHER, Adriana. A construção de letramentos na esfera acadêmica. 2007, $340 \mathrm{f}$. Tese (Doutorado em Linguística)- Universidade Federal de Santa Catarina. Florianópolis. Disponível em: <http://www3.unisul.br/paginas/ensino /pos/linguagem/cd/ Port/3.pdf>. Acesso em: 21 abr. 2012.

FISCHER, Adriana. Letramento acadêmico: uma perspectiva portuguesa. Acta Scientiarum. Language and Culture, v.30, n.2, p.177-187, 2008.

GEE, James Paul. Social linguistics and literacies: ideology in discourses. 2.ed. London: Taylor e Francis, 1996.

KLEIMAN, Ângela B. Ação e mudança na sala de aula: uma pesquisa sobre letramento e interação. In: ROJO, Roxane (Org.). Alfabetização e letramento: perspectivas linguísticas. Campinas, São Paulo: Mercado das Letras, 2002.

MAINGUENEAU, Dominique. Novas tendências em análise do discurso. Belo Horizonte. UFMG, 2005.

MARCONI, Marina de Andrade; LAKATOS, Eva Maria. Fundamentos de metodologia científica. 5ed. São Paulo, 2003.

MARCUSCHI, L. A. Da fala para a escrita: atividades de retextualização. São Paulo: Cortez, 2008a.

MARCUSCHI, L. A. Produção textual, análise de gêneros e compreensão. São Paulo: Parábola Editorial, 2008b.

MATA, Maria Aparecida da. Processos referenciais na retextualização de textos acadêmicos:Faculdade de Letras da UFMG. 2008, 174f. Tese (Doutorado)- Universidade Federal de Minas Gerais, Programa de Pós-Graduação em Estudos Linguísticos.

MATENCIO, Maria de Lourdes Meirelles. Letramento na formação do professor integração a práticas discursivas acadêmicas e construção da identidade profissional. In: CORRÊA, Manoel Luiz G.; BOCH, Françoise. (Org.) Ensino de língua: letramento e representações. Campinas: Mercado de Letras, 2006. 
MATENCIO, Maria de Lourdes Meirelles. Referenciação e retextualização de textos acadêmicos: um estudo do resumo e da resenha. In: CONGRESSO INTERNACIONAL DA ABRALIN, 3, 2003, Anais..., mar. 2003.

MATENCIO, Maria de Lourdes Meirelles; SILVA, Jane Quintiliano Guimarães. Retextualização; movimentos de aprendizagem. ENCONTRO INTERNACIONAL LINGUAGEM, CULTURA E COGNIÇÃO, 2, 2003. Belo Horizonte/Campinas, Faculdade de Educação da UFMG/Faculdade de Educação da UNICAMP, Anais..., Belo Horizonte/ Campinas: Faculdade de Educação da UFMG/Faculdade de Educação da UNICAMP, 2003.

MEDEIROS, J. B. Redação científica: a prática de fichamentos e resenhas. São Paulo: Atlas, 2000.

MOTTA-ROTH, Désirée. Redação acadêmica: princípios básicos. Santa Maria, RS: UFSM/ Imprensa Universitária, 2001.

SCHNEUWLY, Bernard. Gêneros e tipos de discurso: considerações psicológicas e ontogenéticas. In: SCHNEUWLY, Bernard. Gêneros orais e escritos naescola. Tradução e Organização de Roxane Rojo e Glaís de Sales Cordeiro. Campinas, SP: Mercado de Letras, 2004, p.21-39.

STREET, Briani V. Literacy in theory and practice. London: Cambridge University Press, 1984. 